\title{
Transition of University Libraries to Adapt to the New Normal: A mid- and post-COVID-19 Response
}

\author{
Wilfred Jeyatheese Jeyaraj \\ Eastern University, Sri Lanka
}

\begin{abstract}
The aim of this research is to examine the response of university libraries during the COVID-19 outbreak and to establish the practices in carrying out their operational procedures, delivery models, implemented tactics and overall functioning. This study adheres to a quantitative approach. Though, during the pandemic, most of the university libraries were physically inaccessible to readers, they continued to adapt practices to interactively disseminate information and services to its users. Libraries were able to introduce and familiarize their users to new technologies and tools that could adequately serve students and faculty. This study reveals that the efforts and innovations of the libraries and librarians were instrumental in keeping alive the library mission, despite the loss of some services. Hence, this research focuses on revealing the practices adapted, their effectiveness, limitations and presents recommendations for the functioning of an efficient postCOVID-19 University Library framework.
\end{abstract}

Keywords- COVID-19 response, Information Science, Library practices, new normal, University libraries.

\section{INTRODUCTION}

$\mathrm{T}$ This study intends on identifying the challenges experienced by libraries and librarians in a time of crisis, as a result of the COVID-19 pandemic situation. This will focus on what exactly happened to the libraries and their staff members during the crisis, how they managed their resources, services and access to information, and some short-and longterm challenges faced by libraries.

With the pandemic's effects and on the rise, educational activities, public gatherings, local events and several other services were brought to a halt in the efforts of trying to bring the spread of COVID-19 under control by minimizing contact. Adhering to the social-distancing and contactless new-normal situation, Universities and University Libraries were forced to close down their physical services. However, with information being a constant and essential service sought after by several users, libraries had to find alternatives to cope up with pandemic in order to evolve [1].

As such, libraries have started the transition from the print to the digital versions of information resources. There is a need to assess how well our libraries are prepared for this transition. Libraries and their staff have come together with a goal of not only providing access to information, but also educating and training students and researchers on using new technologies during COVID-19.
After battling with the COVID-19 pandemic for nearly 2 years, currently, COVID-19 has been declared as a postPandemic that is no longer an actual pandemic. The majority of the local population, now that the crisis has ceased, are concerned only with the basic life needs. With this, public health officials have warned citizens to be vigilant against rises in the cold-weather flu season coming up in cold countries like United States and Europe due to heavy use of cold weather at home.

Though COVID-19 is still at the brink of a mid-/postpandemic juncture, university libraries are still not fully accessible to its readers as proper mechanisms need to be identified before clients can walk in and refer to resources with ease. Students are receiving their assignments from external sources varying from libraries abroad, consultants, labs to even their own homes via virtual private networks (VPN). Therefore, this research discusses this transition and its effects on the library, Information sciences and its users.

\section{BACKGROUND}

Research on this topic is relatively new as the disease outbreak only came into light roughly a year ago. Recent published resources include factsheets, checklists, presentations and recommendations for libraries on how to deal with the pandemic. However, they lack in the aspect of analyzing the practices that have already been implemented and provide recommendations tailored to transition from the previous manner in which university libraries functioned to the new-normal, using the resources they have, instead of having to completely redesign their practices and serviceproviding methodologies with a lack of resources or budgetary allocations. Some such existing literature on the topic are briefed in this section.

A few universities had the means to transition to digital services, while others were unable to do so and proclaimed locking-down all of their services [2]. Because many institutions followed the instructions relayed from the University's administrative board on how to conduct and oversee online services, the COVID-19 outbreak has caused a rapid transformation in the delivery of information and ultimately, education, throughout the country [3]. This pandemic is causing not just changes in how libraries are delivering information to their users, but also fast policy modifications and actions [4]. 
Adjacent to university libraries, public libraries have also taken a heavy toll due to the pandemic. Though the servicerendering framework of public libraries may slightly vary from that of university libraries, the effects experienced by both these information hubs share commonalities and therefore seek to evolve and adapt new methods in providing services to its users in varying scales [5-8].

Analysis of how university libraries have been functioning during the high-rise of COVID-19 have been conducted in specificity to their countries by some researchers [2-3,9-14]. Pertaining to the Sri Lankan context, [15] has presented concepts that need to be taken into consideration with regard to libraries being prepared for disasters, which rounded off with libraries being prepared to provide uninterrupted services during the COVID-19 pandemic which is also deemed as a disaster.

As such, most of these literary resources have sought out digitization in the process of transitioning all library services mid- and post-COVID-19 [16-20]. The work presented in [21] even goes out to coin this adaptation of libraries to the digital age, midst the pandemic, as the 'infodemic'.

Though various researches have presented a couple of recommendations [22-24], they also come along with challenges and limitations as libraries differ in demographic factors such as their physical location, resources, number and proficiency of library staff, the reader community they serve and many more [25-28]. Hence, these recommendations need to be considered [26-32] and tailored in order to be efficiently encapsulated into the existing framework of a functioning university library.

\section{COVID-19 RESPONSE FROM UNIVERSITY LIBRARIES}

Well before the COVID-19 outbreak, libraries began to transition, if not largely, from tangible to digital resources and services. The digital transition was swiftly addressed by other institutions as well. Existing researches on information behavior also emphasize that the behavior and expectations of readers are fast-changing with the advancement of technology. It can also be observed that not only the way in which people carry out their day-to-day activities, but moreover, the manner in which they seek out requirements and learn new practices are changing midst the pandemic. Similar to other industries, libraries are also transitioning from a physical to a digital paradigm.

If libraries are to maintain their relevance in society, they must catch up with changes brought on by the digital transformation of information societies. The COVID-19 outbreak further catalyzed this transition. Although the idea of moving towards technology seems a viable option for information providers in developed countries, the same digital shift is deemed to be more complicated for libraries in developing and underdeveloped countries.
Furthermore, the current transition of libraries is not limited to physical spaces, but also includes the collection and resourcing of digital materials. As noted by Geiger et al. [33], many libraries have shifted their focus from traditional print collections to digital collections. The COVID-19 outbreak compelled libraries to make the shift even more rapidly.

Digital transitions are also seen in the changing composition of the workforce. According to [34], this transition has resulted in a shift from academic librarians to information workers whose primary roles are to facilitate information search and curation. From the outset, libraries have been at the heart of society's collective memory by storing books, newspapers, photographs, documents, paintings, movies, music files and all other types of media. Digitization is simply an extension of this ideological default in which it is possible to collect information through virtually any means. This result is also brought about by digitalization's ability to store more data in much less space. Digitalization has resulted in many alterations in how people look for information required for their daily activities. As such, university libraries have extended their information collections to accommodate various formats of information resources in addition to their existing digital resources.

Digitalization has also resulted in changes in how libraries are now envisioned. 'The digital library' now includes platforms for e-journals, e-books, digital music, and more. Libraries seek to provide a service that responds to the information needs of its users. The collection of content is tailored with services that are provided on an as-requested basis. This means that the services that are offered must always be up to date. For instance, when a user requests a recent paper from a journal database, the latest version should be made available immediately at the moment of request. In order to do so, university libraries have integrated their network with wellrenowned database providers from around the world, based on the budgetary allocations and constraints in purchasing and extending the services of such database providers, thus, extending the researches, literary writings and valuable information from across the globe, to their local university community and users.

\section{POST-COVID-19 RESPONSE FROM UNIVERSITY LIBRARIES}

Though many universities and university libraries are still functioning in a mid-pandemic manner with remote access and a physical lockdown, nearing the new normal, it is high time that the library administration contemplates a postCOVID-19 service framework for when they reopen.

\section{A. Interaction within the Physical Library Premises}

The core point is that since COVID-19, physical library buildings must be treated as critical infrastructure defending all other critical infrastructures. This means the library management must utilize best practices for protecting the 
building's physical structure and preventing entry by outside parties.

Perceptibly, architecture and design can play an important part in this process, especially in the design of circulation routes, but this is just one aspect of what should also involve other disciplines including faculty, students and staff to determine how they will interact with the building once reopened.

University libraries have come far past the time for administrators to wait on an overarching building design plan which will be pored over by faculty and staff before giving input. Libraries also need to open under these conditions with best practices in place for circulation routes and physical security of the facility.

\section{B. Shelving and Checking-out Tangible Resources}

This also needs to include considerations for shelving, shelving locations, security of shelving within the building itself while taking into account the new normal that is typical of most campuses where many books are checked out.

Resources that are checked-out, need to undergo special treatment before they can be reshelved for reference. This treatment process should take both, COVID-19 sanitization protocols as well as book-preservation and maintenance guidelines. The sanitization treatments should be mindfully carried out such that it does not damage or distort the books.

\section{1) Availability of resources and modification of timelines:}

Including a sanitization protocol within the check-in process of library resources demands a period during which the treated checked-in resources need to be left in isolation. This isolation process means that that particular book cannot be shelved and thus, cannot be referred or checked-out by another library user until the book is safely shelved back for reference.

Hence, university libraries need to ensure one of the following two.

1. The availability of duplicate copies of a particular library resource.

2. The proper notification of the availability of a resource for check-out.

In the case of limited resources, university libraries can adhere to the second guideline and design a timeline, updating the period during which a library resource is available for reference, available for lending, unavailable due to check-out, unavailable due to isolation after check-out, etc.

To rephrase this, the COVID-19 process has become the fulcrum for library planning and planning should be moving forward.

\section{CHALLENGES IN DIGITIZING UNIVERSITY LIBRARY SERVICES}

The way in which library information services are provided have changed alongside the digital transformation of information societies. And this has brought about challenges and limitations in other aspects of maintaining the functionality of university libraries. Such limitations are elucidated here below.

\section{A. Strain on Library Staff}

The transition to digital formats has resulted in different demands on library staff. As more people search for books, magazines, and other reading material on the internet rather than visiting the library, library staff must contend with evolving technology. They must also ensure that there are computers available for those who wish to continue research or other activities within the physical space of the library.

Libraries have traditionally staffed reference or circulation desks, which can generally be staffed by lower-paid staff. The move to digital libraries has meant that many less expensive positions are slowly becoming obsolete as libraries invest in automation, software enhancements and upgraded equipment. In fact, some public libraries now go dozens of days without a single customer visit! This makes it difficult for these libraries to lower their budgets substantially without eliminating what most people would consider essential services.

The challenge that librarians of university libraries face is how to deal with these demands.

\section{B. Unawareness of Readers in Digitally Accessing Library Resources}

Most university libraries maintain an excellent service of reference librarians, who are dedicated to helping students with their research. However, it is increasingly difficult for these librarians to fill the typical roles of finding books for students, helping them navigate through the extensive databases, and providing quick answers to information requests. This is because many students do not know how to effectively search for or access information yet.

The student population is also more diverse than ever before, making it more difficult than ever before to ensure that all of these students can be served instantaneously. With the addition of getting the students and academic staff to search for information on their own demands more times and effort in attempting to educate them, not only on the library cataloguing and accessing system, but also on navigating their way through digital platforms designed specifically for this purpose.

\section{Permission to Access and Disseminate Information}

Besides the two great concerns of information convergence and convergence of electronic and physical platforms, there is a third important point of concern: information localization. From the conventional physical library, there is a movement 
towards globalized digital libraries. The implication of which is that knowledge is no longer limited to one's own national borders. No one can claim to be the sole owner of any information as such knowledge has been shared globally through various online platforms such as Wikipedia and GLAMs (galleries, libraries, archives and museums). However, this phenomenon may not necessarily affect all library users as many users wish to access different kinds of materials from different regions around the world.

However, in bringing information from around the globe, University libraries need to ensure that the information they gather can be disseminated to their library users within the proper licensing and issuing terms. Though most of the digital information such as blogs, videos and some research papers can be found within the public domain, there still exists a number of proprietary information that require the legal acknowledgement and permission of the authors or license holders before sharing publicly or to a specific locality such as the university community.

\section{Synchronization of Distributed Libraries}

Within the new paradigm, libraries are of two kinds: centralized and distributed. Centralized libraries are situated in a particular area or region, while distributed ones are made up of numerous hubs around the globe. Distributed libraries are mainly made up of physical locations found in traditional campus environments, but also available online through various digital platforms. These locations contain collections that are tailored according to geographical boundaries, with users having access to materials that are relevant to their location. A good example would be the British Library which is present in numerous physical locations around the UK and also online on its digital platform. In addition, each location has a website that is managed centrally by the British Library, which provides information on where the library is situated along with its collection and services.

However, maintaining such synchronization between distributed libraries may prove to be more tedious and expensive for libraries in developing and underdeveloped countries. Many universities in such regions already have branch libraries that integrate into the physical system of the main library. In such situations, integrating the resources and services of distributed physical libraries on a digital platform will be a challenge that needs to be overcome.

\section{E. Mass Data Storage and Security Issues}

Furthermore, the whole concept of data storage and retention is also challenging. Whether databases are collected through an application or they are accessed via a Web interface, they are most likely stored in a centralized database that may or may not be connected to the library's local area network. Therefore, it is vital for libraries to ensure that their data is effectively secured, not just for their own sake but also for their clients' protection. Without these security measures in place, there is no doubt that the information collected will be made public by hackers and/or cyber criminals who can use these databases as tools for committing fraud. After the COVID-19 outbreak, the whole world has witnessed how digital technology can exacerbate incidences of violence.

\section{RECOMMENDATIONS}

Based on the current framework and services implemented as an alternative to the COVID-19 restrictions and the limitations faced in completely digitizing university libraries, the following recommendations are proposed to enable the smooth transition into the new normal as libraries reopen their physical facilities and services to their readers.

\section{A. Outsourcing Automation}

There are three main strategies for providing university libraries with information services, namely "to provide them directly, to piggy-back them or to outsource them". Despite the initiatives taken by university libraries to reshape their services, outsourcing services for instance, has been seen as a more effective solution in terms of efficiency and effectiveness. Especially if an institution's number of users is exponential compared with its staffing costs. Moreover, fullyautomating library services is a professional task that demands extreme-proficiency and expertise in software and technology. As such, university libraries can consider outsourcing the task of digitizing their services to software companies that designs or automates such library networks.

Today, most university libraries have a digital library system that can be accessed from a desktop computer or mobile device. Hence, refining the digital access points in order to ease the usage of such facilities will be advisable. Users can be allowed to log into the library's website and download a 'virtual' card that grants them access to books or other materials from within the library via digital means. Universities can also consider introducing an app for mobile devices. In addition, it should be made possible for students to receive an electronic library card as well as use their own personal device to check out materials from the library's catalogue as well as access specific databases.

\section{B. Revision of Key Card Systems}

Additionally, Libraries will also require a new definition of access points into reading rooms that will need revision of traditional card key systems used throughout most universities today. These will need to date back to when the university was closed and the current plan is to retain these systems even with the libraries resuming normal operations. indicate that this does not mean that all of the card key systems need to be retained nor does it mean that traditional key systems should not be considered.

Though this is just a beginning, it may give university administrators an idea of what they should be doing as they work through planning and resuming operations. It may also give faculty, staff and students ideas of how best to prepare and protect themselves and their materials so as to allow 
students and faculty who contact them after COVID-19 to do so in a normal manner once the library has reopened.

\section{C. $\quad$ Resource Isolation}

Since sanitization of library resources in isolation is still an emerging practice, libraries will need to adapt guidelines and best practices within their unique operational contexts. Hence, there is no existing protocol for such methodologies that can be readily applied by all organizations.

There are three major technical or logistical challenges that pose the greatest threat in the implementation of such a system.

1. The availability of resources due to check-out within the library system, when the resources are undergoing sanitization and isolation.

2. The validity period of a library resource being checkedout by a particular user.

3. The ability to access a sanitized and isolated book outside of the library system.

In order for a sanitization protocol to be effective, these need to be addressed and ideally, resolved within the most appropriate amount of time.

\section{1)Personal Identification Number:}

One possible solution would be to configure each library resource with a unique personal identification number (PIN) that is used in conjunction with an authentication process in order to find the resources in the system when it is needed. In order for this PIN system to work effectively, it will need to be integrated within the ILS (Integrated Library System) or ISMS (Information Security Management System) of each library's online delivery system.

Once the resources are checked-in into the system, each library resource needs to be automatically blocked until it passes through an isolation module that performs a sanitization process.

\section{General Recommendations before Reopening Libraries}

The following lists out the recommendations that need to be taken into consideration when reopening university libraries following the COVID-19 pandemic.

1. Ensure COVID-19 can no longer be contracted from paper.

2. Leave a stock of disinfectant in the library, and keep paper handling to a minimum.

3. Remove any furniture that comes into contact with books or other items, and sanitize it thoroughly before reuse.

4. Research any organization that holds links to the University Library website for updated links and passwords.

5. Remove any items on the shelves that may have had contact with COVID-19 such as books and journals.
6. Ensure that any resources stored in the library remain in the library and not removed outside of it.

7. Ensure that any resources returned to the library by students, staff or alumni remain within the library and not taken outside of it.

8. Permit staff and students access to photocopiers and scanners without requiring them to interrupt their work for disinfection.

9. Permit access to live chat software without requiring people to shower before using it.

10. Leave a stock of paper towels and sanitizers for users to use when cleaning their hands before referring to tangible resources and accessing digital content via physical library properties.

These are mere guidelines that need to be adhered to during this pandemic as well as the preparatory process for the new normal following the post-COVID-19 situation. However, university libraries need to consider their existing infrastructure as well as the resources available at hand in order to smoothly transition and adapt an efficient system that works for them in particular.

\section{CONCLUSION}

The goal of this study is to evaluate the practices of university libraries during the COVID-19 pandemic and to establish strategies towards the implementation of its services and facilities in order to adapt an alternative during the new normal situation. This paper elucidates the methodologies that university libraries had followed in coping up during the highrise of the pandemic, the services expected to be brought into practice during the post-COVID-19 era and discusses the challenges that libraries can face in transitioning from their existing framework to a digital platform which is presented as the most-sought-out solution. Based on these identified limitations, this study presents a set of viable recommendations to ease the shift from physical to digital paradigm with the consideration of available resources as well as COVID-19 protocols.

\section{REFERENCES}

[1] Weiss, S. R. (2020). Forty years with coronaviruses. The Journal of experimental medicine, 217(5).

[2] Rafiq, M., Batool, S. H., Ali, A. F., \& Ullah, M. (2021). University libraries response to COVID-19 pandemic: A developing country perspective. The Journal of Academic Librarianship, 47(1), 102280.

[3] Ifijeh, G., \& Yusuf, F. (2020). Covid-19 pandemic and the future of Nigeria's university system: The quest for libraries' relevance. The Journal of Academic Librarianship, 46(6), 102226.

[4] Asif, M., \& Singh, K. K. (2020). Trends, opportunities and scope of libraries during Covid-19 pandemic. IP Indian Journal of Library Science and Information Technology, 5(1), 24-27.

[5] Alajmi, B. M., \& Albudaiwi, D. (2020). Response to COVID-19 Pandemic: Where Do Public Libraries Stand?. Public Library Quarterly, 1-17.

[6] Goddard, J. (2020). Public libraries respond to the COVID-19 pandemic, creating a new service model. Information Technology and Libraries, 39(4).

[7] Matthews, J. R. (2020). COVID-19 and public libraries: A real paradigm shift. 
[8] Haasio, A., \& Kannasto, E. (2020). Covid-19 and its impact on Finnish public libraries. Qualitative and Quantitative Methods in Libraries, 3-19.

[9] Tammaro, A. M. (2020). COVID 19 and Libraries in Italy. International Information \& Library Review, 52(3), 216220

[10] Guo, Y., Yang, Z., Yang, Z., Liu, Y. Q., Bielefield, A., \& Tharp, G. (2020). The provision of patron services in Chinese academic libraries responding to the COVID-19 pandemic. Library Hi Tech.

[11] Fasae, J. K., Adekoya, C. O., \& Adegbilero-Iwari, I. (2020). Academic libraries' response to the COVID-19 pandemic in Nigeria. Library Hi Tech.

[12] Temiz, S., \& Salelkar, L. P. (2020). Innovation during crisis: exploring reaction of Swedish university libraries to COVID19. Digital Library Perspectives.

[13] Gmiterek, G. (2021). Polish university libraries social networking services during the COVID-19 pandemic spring term lockdown. The Journal of Academic Librarianship, 47(3), 102331.

[14] Yu, F., \& Mani, N. (2020). How American academic medical/health sciences libraries responded to the COVID-19 health crisis: An observational study. Data and Information Management, 4(3), 200-208.

[15] Wijayasundara, N. D. (2021). Disaster Preparedness in Sri Lankan University Libraries: Before COVID-19. Journal of the Australian Library and Information Association, 1-17.

[16] Mehta, D., \& Wang, X. (2020). COVID-19 and digital library services-a case study of a university library. Digital library perspectives.

[17] Pambayun, K. G. (2021). Digital Libraries during Covid-19 Pandemic: A Bibliometric Analysis and Information Mapping. Indonesian Journal of Librarianship, 17-30.

[18] Martínez-Cardama, S., \& Pacios, A. R. (2020). Twitter communication of university libraries in the face of Covid-19. El Profesional de la Información, 29(6).

[19] Samanta, M. (2020). Library access policies post COVID-19 pandemic. Available at SSRN 3610042

[20] Nawaz, N., Gomes, A. M., \& Saldeen, M. A. (2020). Artificial intelligence (ai) applications for library services and resources in covid-19 pandemic. Artificial intelligence (AI), 7(18), 1951-1955.
[21] Naeem, S. B., \& Bhatti, R. (2020). The Covid-19 'infodemic': a new front for information professionals. Health Information \& Libraries Journal, 37(3), 233-239.

[22] Mestri, D. D. (2020). Reopening libraries in COVID 19 pandemic: challenges and recommendations. Journal of Advances in Library and Information Science, 9(2), 36-45.

[23] Martzoukou, K. (2020). Academic libraries in COVID-19: a renewed mission for digital literacy. Library management.

[24] Santos, M. C. (2020). Libraries respond to COVID-19. Texas Library Journal, 96(2), 64-73.

[25] Smith, J. (2020). Information in crisis: Analysing the future roles of public libraries during and post-COVID-19. Journal of the Australian Library and Information Association, 69(4), 422-429.

[26] Pokorná, L., Indrák, M., Grman, M., Stepanovsky, F., \& Smetánková, M. (2020). Silver lining of the COVID-19 crisis for digital libraries in terms of remote access. Digital Library Perspectives.

[27] Craft, A. R. (2020). Remote work in library technical services: Connecting historical perspectives to realities of the developing COVID-19 pandemic. Serials Review, 46(3), 227-231.

[28] Holland, B. (Ed.). (2021). Handbook of Research on Library Response to the COVID-19 Pandemic. IGI Global.

[29] Tsekea, S., \& Chigwada, J. P. (2020). COVID-19: strategies for positioning the university library in support of e-learning. Digital Library Perspectives.

[30] Pionke, J. J. (2020). COVID-19, accessibility, and libraries: A call to action. College \& Research Libraries News, 81(8), 398.

[31] Ali, M. Y., \& Gatiti, P. (2020). The COVID-19 (Coronavirus) pandemic: reflections on the roles of librarians and information professionals. Health information \& libraries journal, 37(2), 158162.

[32] Okike, B. I. (2020). Information dissemination in an era of a pandemic (COVID-19): librarians' role. Library Hi Tech News.

[33] Geiger, C. (2013). Copyright and Digital Libraries: Securing Access to Information in the Digital Age1. In Digital Rights Management: Concepts, Methodologies, Tools, and Applications (pp. 99-114). IGI Global.

[34] Becker-Redd, K., Lee, K., \& Skelton, C. (2018). Training student workers for cross-departmental success in an academic library: A new model. Journal of Library Administration, 58(2), 153-165. 